\title{
Koplik spots revisited
}

\section{Sheela Xavier MBBS DCH, Sarah E.D. Forgie MD}

Competing interests: None declared.

This article has been peer reviewed. patient consent.

Affiliations: Department of University of Alberta,

Edmonton, Alta.

\section{Correspondence to}

Sarah Forgie,

sforgie@ualberta.ca

CMAJ 2015. DOI:10.1503 /cmaj.141656

A
The authors have obtained Pediatrics (Xavier, Forgie), n otherwise healthy, fully vaccinated, 10-month-old girl presented to the emergency department after seeing her family physician with a one-day history of rash.

The patient had been exposed to someone with confirmed measles on a domestic flight two weeks earlier. She was alert but febrile on physical examination, and she had a red maculopapular rash coalescing on her face with discrete lesions on her trunk. The patient had multiple 2-4 $\mathrm{mm}$ bluish-white plaques on a red background on her buccal mucosa (Figure 1). Further testing confirmed the patient had measles.

Measles, a notifiable disease in Canada, is spread by airborne and droplet routes with an incubation period of $10-12$ days. ${ }^{1}$ The diagnosis is confirmed with serology (immunoglobulin M or a four-fold rise in convalescent immunoglobulin $\mathrm{G}$ ), or detection of the virus (by culture or nucleic acid testing) in the nasopharynx or urine. ${ }^{1}$ Early symptoms occur two to four days before the

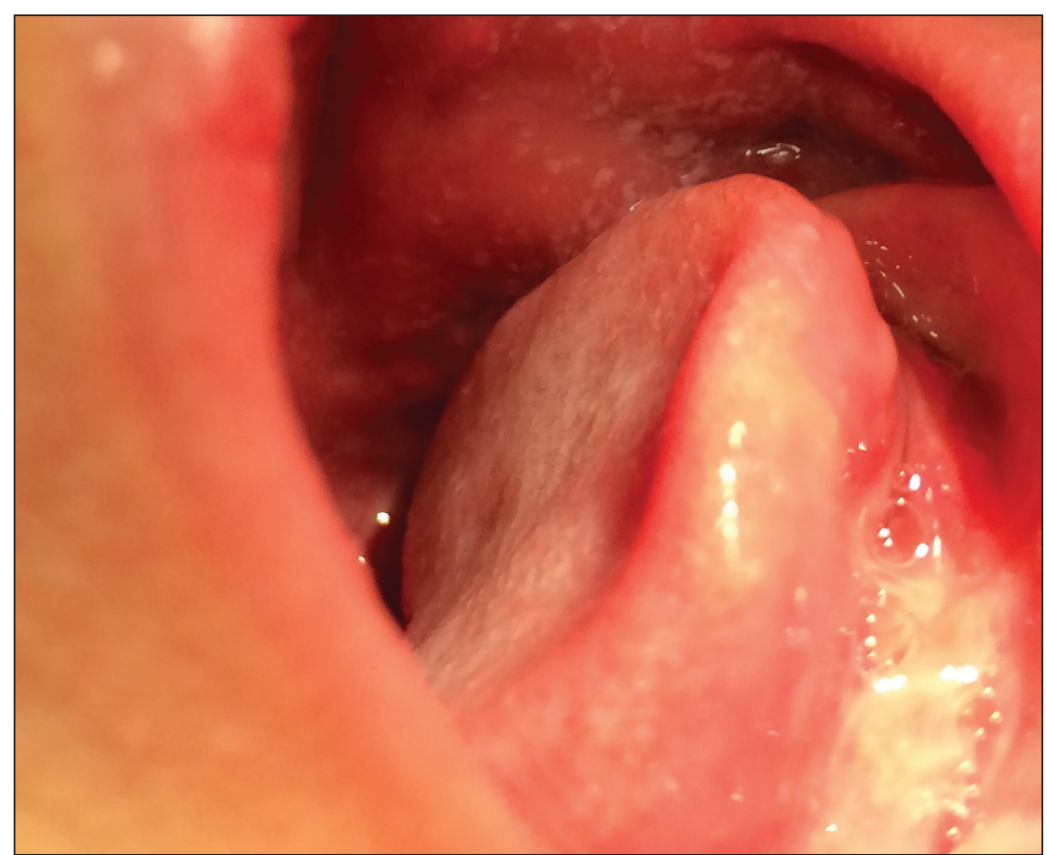

Figure 1: Photograph showing Koplik spots on the buccal mucosa of a 10-month-old girl who had been exposed to the measles virus two weeks before her presentation. The patient was later confirmed to have measles. exanthem and include fever, cough, coryza and conjunctivitis; in addition, Koplik spots can appear one to four days before the widespread rash. ${ }^{1}$ Although Koplik was not the first to describe his eponymous spots, he emphasized their association with measles, their evolving appearance and their importance in infection control. ${ }^{2}$

Koplik spots start as bluish-white "grains of salt on a red background" opposite the molars on the buccal mucosa. They may also appear on conjunctival folds or on vaginal or gastrointestinal mucosa. ${ }^{3}$ The bluish-red halo is caused by a collar of dilated veins around the submucosal gland duct, whereas the white portion is likely the result of the destruction of glandular epithelial cells. ${ }^{4}$ Koplik spots are present in more than $70 \%$ of patients with measles, ${ }^{3}$ and "the height of the eruption is reached just as the skin eruption has appeared and is spreading." ${ }^{5}$ As the widespread rash progresses, the rash on the mucosal membrane loses "the character of discrete spotting and [becomes] a diffuse red background with innumerable bluish white specks scattered on its surface." ${ }^{5}$ Ultimately, the mucous membrane reverts back to its normal appearance well before the skin eruption resolves. Differential diagnosis of Koplik spots includes Fordyce aphthae (which lack a bright red background), aphthous ulcers (which are painful and less numerous) and parvovirus B19 infection. ${ }^{6,7}$

\section{References}

1. Public Health Agency of Canada. Guidelines for the prevention and control of measles outbreaks in Canada. Can Commun Dis Rep 2013;39. Available: www.phac-aspc.gc.ca/publicat/ccdr-rmtc /13vol39/acs-dcc-3/assets/pdf/meas-roug-eng.pdf (accessed 2015 Feb. 26).

2. Koplik H. A new diagnostic sign of measles. $\operatorname{Med} \operatorname{Rec}(N Y) 1898$; 53:505-7.

3. Lefebvre N, Camuset G, Bui E, et al. Koplik spots: a clinical sign with epidemiological implications for measles control. Dermatology 2010;220:280-1.

4. Brem J. Koplik spots for the record. An illustrated historical note. Clin Pediatr. 1972;11:161-3.

5. Koplik H. The diagnosis of the invasion of measles from a study of the exanthema as it appears on the buccal mucous membrane. Arch Pediatr 1962;79:162-5.

6. Jenson HB, Baltimore RS. Pediatric infectious diseases: principles and practice. 2nd edition. Philadelphia: W.B. Saunders Company; 2002.

7. Evans LM, Grossman ME, Gregory N. Koplik spots and a purpuric eruption associated with parvovirus B19 infection. J Am Acad Dermatol 1992;27:466-7. 